\title{
Continental Portuguese Territory Flood Social Susceptibility Index
}

\author{
N. Grosso, L. Dias, H. P. Costa, F. D. Santos, and P. Garrett \\ CE3C - Centre for Ecology, Evolution and Environmental Changes, Faculdade de Ciências, Universidade de Lisboa, \\ 1749-016 Lisbon, Portugal
}

Correspondence to: N. Grosso (nunogro@gmail.com)

Received: 13 November 2014 - Published in Nat. Hazards Earth Syst. Sci. Discuss.: 15 December 2014

Accepted: 13 July 2015 - Published: 26 August 2015

\begin{abstract}
The combination of human exposure, extreme weather events and lack of adaptation strategies to cope with flood-related impacts can potentially increase losses not only on infrastructure but also on human lives. These impacts are usually difficult to quantify due to the lack of data, and for this reason most of the studies developed at the national scale only include the main characteristics that define the societal or individual predisposition to be affected, resist, adapt or recover, when exposed to a flood.

The main objective of this work was to develop a flood social susceptibility index for the continental Portuguese territory based on the most representative variables able to characterize different influencing factors. This index is a component of the national vulnerability index developed in the scope of Flood Maps in Climate Change Scenarios (CIRAC) project, supported by the Portuguese Association of Insurers (APS).

The main results showed that the proposed index correctly identified populations less prepared to avoid flood effects or able to cope with them, mostly concentrated in rural inland areas with lower income and education levels when compared with the coastal region between Viana do Castelo and Setúbal.
\end{abstract}

\section{Introduction}

The number of natural disasters as well as the number of people affected by them has been increasing in the last decades, showing that societies are currently more vulnerable and exposed to these phenomena (Ge et al., 2013). Extreme climate events are responsible for $80 \%$ of the damage caused by those natural disasters worldwide, with floods affecting more than a billion people in the last decade and causing thousands of deaths every year (Vörösmarty et al., 2013). In Europe, floods, together with windstorms, are the most frequent natural disaster and their damages correspond to a third of total economic losses related to these types of phenomena (EEA et al., 2008; IPCC, 2012).

In the last decades the frequency and intensity of natural extreme events has been increasing (Ge et al., 2013) as a result of climate-change-induced changes in climatic patterns, which, most likely, will be aggravated in the next years (e.g. Hov et al., 2013; IPCC, 2012).

For this reason, vulnerability assessment techniques are becoming a fundamental tool in flood risk management, helping to define more effective risk reduction strategies and promoting societal disaster resilience (Birkmann, 2006). The concept of vulnerability was introduced in the 1970s in the context of social sciences and was originally oriented to the risk perception related to catastrophes (Birkmann, 2006). Currently, there are several definitions derived from the different application scopes of application of the scientific communities behind them (Veen et al., 2009, Thywissen, 2006).

In general, vulnerability can be defined as the loss potential of assets or individuals when exposed to a natural disaster of a certain magnitude (Ionescu et al., 2009; Cutter et al., 2000; Schanze et al., 2006). This definition covers several vulnerability dimensions, namely, physical, social, economic, politic, cultural and environmental that, when aggregated with a physical component (Thywissen, 2006), form a composed vulnerability index (see e.g. Balica et al., 2012; Sebald, 2010). This scope has been expanding to include nowadays concepts such as coping capacity and resilience (Armaş and Gavriş, 2013). The work presented here refers solely to the social component of this composed index.

Nowadays, there are still many difficulties to determine the flood loss potential due to the lack of data to estimate the af- 
fected area and their associated costs, mainly at the national level. For that reason, most of the studies developed at this scale only include the main characteristics that define the societal or individual predisposition to be affected, resist, adapt or recover, when exposed to a flood (Ge et al., 2013; Armaş and Gavriş, 2013). In the opinion of the authors of this paper, this characterization, also adopted here, is better suited to define flood social susceptibility (FSS) and therefore the developed index was designated as a social susceptibility index (SSI). Nevertheless the adopted methodology derives from the existing bibliography on flood vulnerability indexes.

\section{State of the art}

There are usually two different methodologies to evaluate flood social vulnerability: (a) the SoVI (social vulnerability index) model and (b) the SeVI (social vulnerability assessment using spatial multi-criteria analysis) model. The first was developed by Cutter et al. (2003) and uses principal component analysis (PCA) to select the most representative indicators to compose the final index, without providing different variable weights. Since its formulation, this method has been widely used in the United States and more recently in Europe, becoming the standard vulnerability assessment method (Armaş and Gavriş, 2013; Ge et al., 2013). The second is based on a multicriteria analysis developed by Saaty (1980) called analytical hierarchical process (AHP). This method combines expert evaluation and statistical methods to determine the relative weight for each variable.

The main objective of this work is to develop a SSI for the Portuguese territory based on the approach initially proposed by Cutter et al. (2003) and further developed by Fekete (2010). Although there are some studies in other European countries to develop national flood vulnerability indexes, in Portugal there is only one published social vulnerability index for some municipalities, implemented by de Oliveira Mendes (2009), that includes both natural and technological risks and does not differentiate floods.

The results presented here are part of a composed flood vulnerability index for continental Portugal developed in the scope of the CIRAC project (Flood Risk Mapping in Climate Change Scenarios http://siam.fc.ul.pt/cirac/). This index also includes the exposure and physical susceptibility components, which are explained in more detail in a companion paper (Jacinto et al., 2015).

\section{Materials and methods}

\subsection{Study area}

Continental Portugal, situated in the southwest of Europe, is part of the Iberian Peninsula and occupies an area of $89015 \mathrm{~km}^{2}$, currently divided into 5 NUTS II regions, 278 municipalities and 2882 parishes. In 2001 the number of parishes was significantly higher (4037) and only decreased to the current number in 2013, after a national administrative reorganization process (INE, 2011) (Fig. 1).

According to the 2011 census data (INE, 2011), its number of inhabitants increased approximately $2 \%$, between 2001 and 2011, from 9869343 to 10047083 , which represented a decrease in the growth rate, when compared to the $5 \%$ registered in the previous decade. From the 278 municipalities, 171 in 2001 and 198 in 2011 have registered a decrease in population, contributing to an imbalance in population spatial distribution (INE, 2001), with an overall movement from rural to urban municipalities. In the last decades, the migratory movements from inland to coastal areas within the Portuguese territory, together with emigration, mostly from rural areas during the 1970s, and, more recently, the emigration phenomena to urban areas, first from the Portuguese former colonies (starting from 1976 onwards), and, in the last decade, from EU eastern countries, Brazil and Asia contribute to this tendency.

In parallel, other demographic phenomena have intensified in Portugal. On the one hand, according to the 2011 census, the double aging of the population process, characterized by a decrease in youth population and an increase in older aging groups, has continued to strengthen in the last 40 years. The total dependency index, defined by ratio between the sum of the population in the 0-14 and over 65 age groups and the active population, defined by the 15-64 age group, has increased $4 \%$ in the last decade, supported solely by the $21 \%$ growth in the older population.

On the other hand, in the last 10 years, two factors had a positive evolution: education and income. Regarding the first, the percentage of people with higher education almost doubled, going from approximately 6 to $12 \%$ (INE 2011), while the percentage of people with no education or only basic education cycles completed (first to sixth grade) decreased from 67 to $57 \%$. Nevertheless, there is still a significant regional imbalance in the evolution of the Portuguese population educational level, with more highly educated people usually more concentrated in the coastal urban municipalities. As for average annual income, statistics show an increase from EUR 7294 in 2000 to EUR 10838 in 2011. The spatial distribution of average income also highlights the same coastal/inland differences shown for other indicators.

Unemployment rate is another important socioeconomic factor to characterize flood social vulnerability in continental Portugal. In the last 10 years, this rate has risen significantly from 6.8 to $13.2 \%$, mostly after the 2008 crisis, after 20 years of low and stable values

In summary, this characterization shows a slow growing and aging country with increasingly lower birth rates, higher education and higher income. Also highlighted by these indicators is the existence of significant regional inequalities between the densely populated, more educated and richer coastal urban areas and the depopulating, less educated, poorer inland rural regions. This snapshot of the con- 
(a)

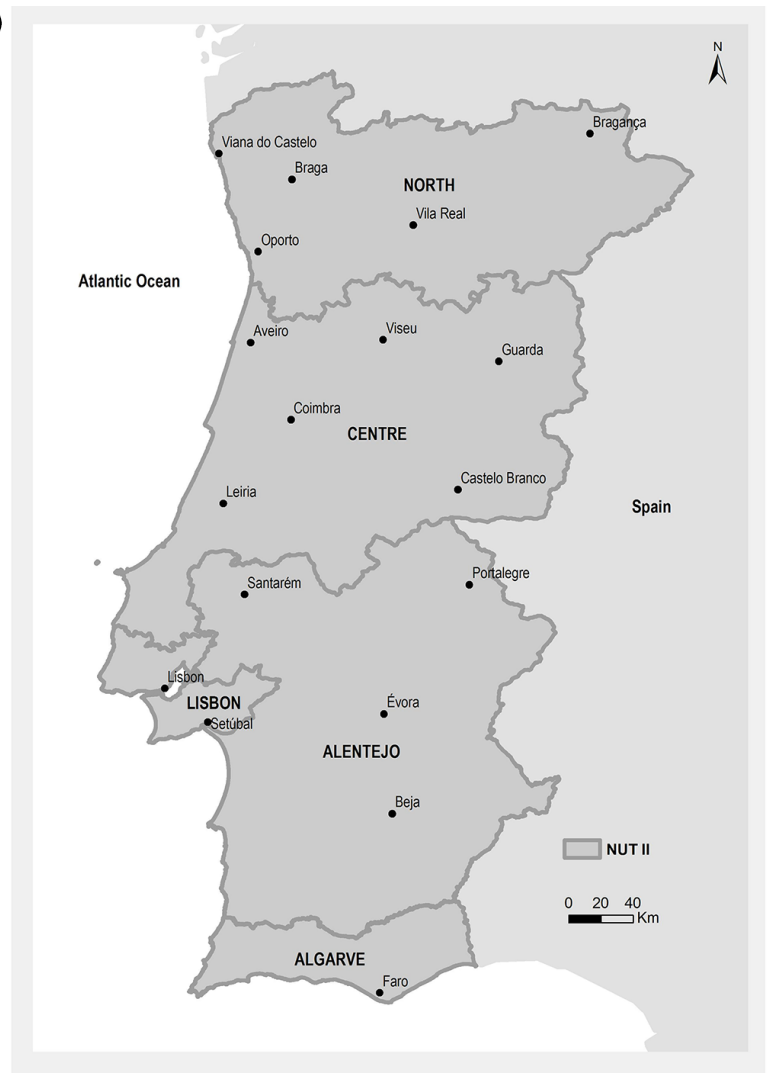

(b)

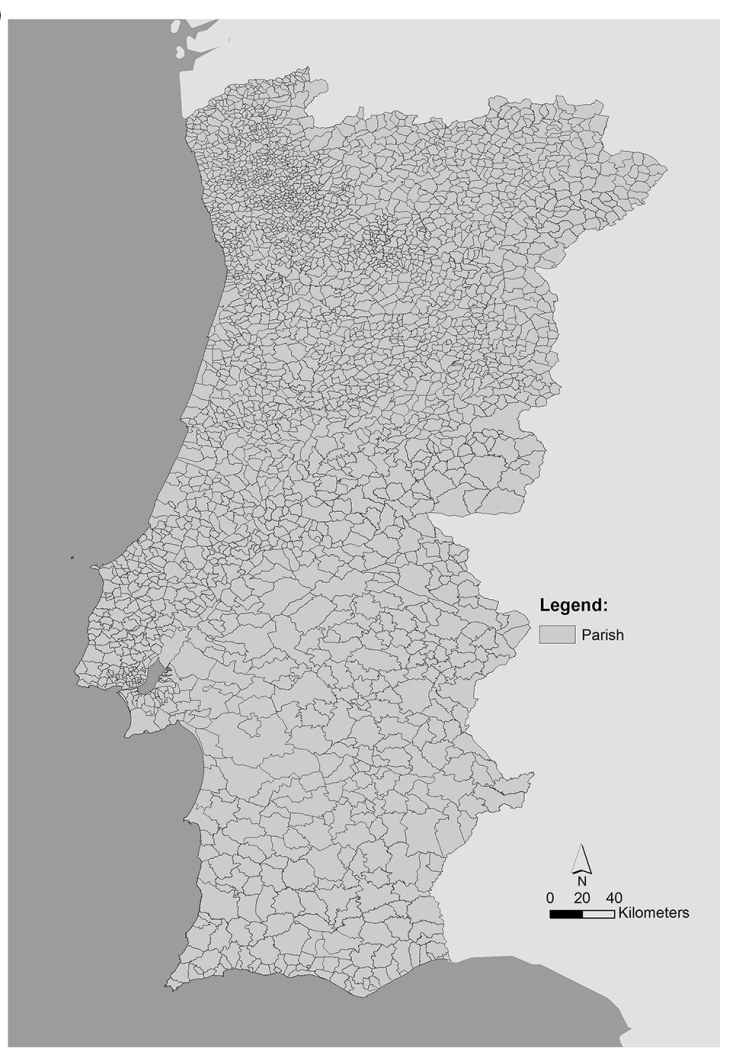

Figure 1. Characterization of the study area - (a) Portuguese NUTS II regions, main cities and municipalities and (b) Portuguese parishes.

tinental Portuguese territory will surely be reflected in the social vulnerability index described in the next sections.

\subsection{Data sets}

Table 1 presents the 39 variables used initially in this study, providing information on its origin, production year, the abbreviation used in this study to label them, as well as information on the indicator group they represent and a first evaluation of its role in flood social susceptibility characterization. This evaluation is represented by one or two minus signs in the case of variables that increase social susceptibility; one or two plus signs if a variable decreases it; and one minus and one plus signs, where variables can play both a positive and negative role in flood social susceptibility. The evaluation of each indicator was made by the authors, following a similar analysis made in the work of Feteke (2010). Nevertheless, as in any variable selection process, there is some degree of subjectivity that should be taken in consideration when evaluating the results of this flood social susceptibility index. Regarding the label, it should be noted that the abbreviations of the final normalized variables used in the composition of the index are equal to the ones presented in the table but with the prefix "NORM".
The selection of indicators took into account their ability to characterize the relevant socioeconomic (e.g. age, income, dependence) and built environment characteristics (building age and typology) for flood social susceptibility assessment in the different parishes of the continental Portuguese territory.

Whenever possible, data sets of similar origin were used to assure input data homogeneity in the development of the final index. For that reason most of the selected data refer to the 2001 census. The 2011 census was not included in this study because only provisional data were available at the time. In the authors' opinion, although this is a limitation of the study, it does not compromise the results presented here. In the last 10 years only the magnitude, not the spatial distribution, of each parameter within the Portuguese territory has changed significantly, rendering the comparison between the different parishes still valid. Whenever the required indicators were not available through 2001 census data, alternative data sets were used, available in the statistical yearbooks published by Statistics Portugal (INE, 2010a, b, c, d, e) or by other governmental sources (IGP, 2010). All the values were originally provided at parish level, except in the cases indicated in the table footnotes, where calculations had to be performed to adjust to this scale. In the specific cases of the dependency 
Table 1. Variables used in this study (with the exception of the percentage of urban area all data were obtained from Statistics Portugal).

\begin{tabular}{|c|c|c|c|c|}
\hline Description & Name & Weight & Group & Year \\
\hline Buildings with concrete structure & EBAR & ++ & $\begin{array}{l}\text { Building construction } \\
\text { typology }\end{array}$ & 2001 \\
\hline Buildings with walls of masonry mortar & EARG & -+ & & 2001 \\
\hline Buildings with walls of stone adobe or pug masonry & EPAT & -- & & 2001 \\
\hline Buildings with other resistance elements (wood, metal) & EORE & -- & & 2001 \\
\hline Exclusively residential buildings & ER & -- & Building function & 2001 \\
\hline Mainly residential buildings & PR & -+ & & 2001 \\
\hline Traditional families without unemployed & FCD_0 & ++ & Income & 2001 \\
\hline Traditional families with one unemployed & FCD_1 & -+ & & 2001 \\
\hline Employed population & IR_EP & ++ & & 2001 \\
\hline Unemployed population seeking first employment & IRD'E & - & & 2001 \\
\hline Unemployed population seeking new employment & IRDNE & -- & & 2001 \\
\hline Not economically active population & IR_SAC & -+ & & 2001 \\
\hline Foreign population with legal resident status (no UK) & IMIG_VAR & - & & 2010 \\
\hline Guaranteed minimum income $\mathrm{a}^{\mathrm{a}}$ & RSI & -- & & 2010 \\
\hline Percentage of social housing buildings & HAB_SOCIAL & - & & 2010 \\
\hline Monthly net average wage $\mathrm{a}^{\mathrm{a}}$ & GMMTCO & + & & 2009 \\
\hline Average annual value of pensions ${ }^{a}$ & VMAP & + & & 2010 \\
\hline Traditional families with people with younger than 15 & FCPME15 & - & Dependent & 2001 \\
\hline Traditional families with people 65 and older & FCPMA65 & -- & & 2001 \\
\hline Families with children under 6 years old & NFF6 & - & & 2001 \\
\hline Child dependency ratio & IND_DJ & - & & 2001 \\
\hline Aged dependency ratio ${ }^{b}$ & IND_DI & - & & 2001 \\
\hline Total dependency ratio ${ }^{b}$ & IND_DT & - & & 2001 \\
\hline Resident population between 0 and 4 years old & R0_4 & -- & Age & 2001 \\
\hline Resident population between 5 and 9 years old & R5_9 & -- & & 2001 \\
\hline Resident population between 10 and 13 years old & R10_13 & - & & 2001 \\
\hline Resident population between 14 and 19 years old & R14_19 & + & & 2001 \\
\hline Resident population between 20 and 64 years old & R20_65 & ++ & & 2001 \\
\hline Resident population 65 years and over & R65 & -- & & 2001 \\
\hline Retired persons and pensioners & IR_PR & - & & 2001 \\
\hline Residents with no qualification & IRQA_001 & -- & Education & 2001 \\
\hline Residents with first cycle of basic education & IRQA_110 & - & & 2001 \\
\hline Residents with second cycle of basic education & IRQA_120 & + & & 2001 \\
\hline Residents with third cycle of basic education & IRQA_130 & ++ & & 2001 \\
\hline Residents with secondary education & IRQA_200 & ++ & & 2001 \\
\hline
\end{tabular}

a Value given for the entire municipality and calculated for the parish by considering the original value by the percentage of area each parish represents in the municipality.

$\mathrm{b}$ Calculated from the 2001 census (population $-n /$ parish area $-\mathrm{km}^{2}$ ).

ratios the values were calculated based on the 2001 census and refer to the following:

1. youth dependency ratio (IND_DJ) - defined by ratio between the sum of the population in the $0-14$ age groups and the active population, defined by the 15-64 age group;

2. aged dependency ratio (IND_DI) - defined by ratio between the sum of the population in the over 65 age groups and the active population;
3. total dependency ratio (IND_DT) - the ratio between the sum of the population in the $0-14$ and over 65 age groups and the active population.

\subsection{Methods}

The methodology adopted to develop the Portuguese flood social vulnerability index was based on the work of Fekete (2010), and it is comprised of four main stages: 
a. pre-selecting census data variables that could better describe social vulnerability to floods in continental Portugal (Table 1) and characterizing their role and influence;

b. using principal component analysis to define the variables or group of variables that better represent the different components of flood social susceptibility;

c. aggregating those variables into indicators, according to the components defined in the previous step (This aggregation takes into account the role and influence in flood social susceptibility of the variables (subtracting the sum of the negative ones from the sum of the positive variables).);

d. composing the final index by summing the different components. This methodology follows the SoVI model, an approach perceived as more appropriate for this study, since it provides a less subjective selection procedure of the most representative variables in large data sets.

The variable pre-selection step consisted of an analysis made by the authors, comparing the statistical data sets available for the Portuguese territory with the most relevant factors, identified in previous studies (e.g. Vörösmarty et al., 2013; Fekete, 2010; Azar and Rain, 2007; Cutter et al., 2003), influencing flood social susceptibility: age, income, education, urban/rural background and building function/typology.

After arriving at the final set of variables, shown in Table 1, a PCA was performed, using SPSS 20, to reduce data set dimensionality to the variables that summarize the main characteristics of flood social susceptibility (Field, 2007). In parallel, analysing the variables with higher loadings within the main final components variables can help derive a set of indicators that define a social susceptibility profile (Fekete, 2010). Before performing the PCA, a standardization procedure was implemented to render the variable values between different parishes comparable. The standardization reference values differed, according to the different variables:

a. building construction and typology variables were normalized by the total number of buildings;

b. family-income-related data sets by the total number of families;

c. employed and unemployed population variables by the total number of economically active people;

d. the not economically active population by the 2001 total population;

e. the foreign population variables and the number of people receiving guaranteed minimum income were divided by the 2010 total population; f. the percentage of social housing buildings by the 2010 total number of buildings;

g. monthly net average wage and average annual pensions were not normalized because they already averaged values;

h. all gender, age and education variables were normalized by the total number of residents; and

i. the total, aged and youth dependency ratios, percentage of urban area and population density are already normalized values. All the reference values are given at the parish scale for the same year of the data set being normalized.

After standardization, a variable correlation matrix was computed to identify cases of extreme multicollinearity, defined as the variables pairs with an absolute value of the Pearson's correlation coefficient $R$ higher than 0.9 . In these cases two variables have very similar behaviours and therefore their individual contribution cannot be assessed correctly within the PCA and therefore one of those variables is excluded from the analysis.

The PCA was applied with the remaining variables using a full model approach (all variables included) in a Varimax rotation with Kaiser normalization to maximize the sum of the variances of the squared loadings of each variable across the different components, providing a higher loading in a specific component and lower on the remaining. This method provides a clearer interpretation of the correspondence between variables and components. The selection of the final set of variables was established on three criteria based on PCA outputs:

- The overall Kaiser-Meyer-Olkin measure of sampling adequacy (KMO statistic) (Kaiser, 1974) should be higher than 0.5 (Hutcheson and Sofroniou, 1999). This statistic provides a general measure of the adequacy of the collected data to perform a factor analysis, based on their correlation matrices. A value higher than 0.5 is considered to be the minimum value to consider that the included variables share a significant common variance and therefore can be further reduced through factor analysis. If the KMO value is lower, individual variables should be dropped, preferentially the ones with lower communality values, a measure of how well each variable is represented in the different components.

- The diagonal values of the anti-image correlation matrix should also be greater than 0.5 . The anti-image correlation matrix contains the negative of the partial correlation coefficients between each pair of variables. The diagonal of this matrix provides the individual KMO statistics; when one of its values is below the 0.5 threshold, one of the two variables involved should be excluded since this means that they are not well factored into the principal components (Feteke, 2010). 
- The off-diagonal values of the anti-image correlation matrix, representing the negative of the partial correlations between variables, should be as small as possible in a good factor model (Field, 2007). A threshold value of 0.6 was established for this study (Feteke, 2010). If lower values are found one of the involved variables should be excluded.

These three criteria were applied in the order they are presented in this paper and whenever one variable was excluded, the PCA was reprocessed, since removing one variable changes the final model and it is necessary to recalculate all statistics.

After arriving at a final model, the final set of principal components was chosen based on an evaluation of the eigenvalues, a measure of the standardized variance associated with a particular factor. Only the components with an eigenvalue higher than 1 were included as flood social susceptibility indicators. Each variable was attributed to one of those specific components, based on their highest loading value. A lower threshold loading value of 0.5 was defined to consider that a certain variable is strongly factored into a component. The final flood social susceptibility indicators were identified by interpreting the final variables groups of each component and their respective signs.

From the variables contained in each component/indicator, only two variables with a positive influence on flood social susceptibility and two with a negative influence were chosen to be included in the index, based on their highest loadings. To arrive at the final values per parish of each of the identified indicators, the values of the corresponding variables were aggregated by calculating the difference between the averaged sums of the variables with positive and negative influence, as can be seen in Eq. (1) (adapted from Feteke, 2010):

Indicator $=\frac{\sum \operatorname{Var}_{\mathrm{p}}}{N_{\mathrm{P}}}-\frac{\sum \operatorname{Var}_{\mathrm{N}}}{N_{\mathrm{N}}}$,

where $\operatorname{Var}_{P}$ and $\operatorname{Var}_{N}$ correspond to the values of the variables with positive and negative influence, and $N_{\mathrm{P}}$ and $N_{\mathrm{N}}$ to their respective number of variables. All variables were previously normalized to a 0 to 1 scale, based on their minimum and maximum values. Therefore, the final indicator values varied between -1 (indicating higher flood social susceptibility) and 1 (lower).

The final step was to aggregate the different indicators into the final flood susceptibility per parish index by summing the values of all indicators. Since all indicator values could theoretically vary from -1 to 1 , the index can vary between $-N$ (highest flood social susceptibility) to $N$ (lowest), where $N$ is the total number of indicators.

\section{Results and discussion}

This results section is divided into two parts. The first focuses on the description of the main PCA results that established
Table 2. Variable pairs within the correlation matrix with extreme multicollinearity $(|R| \geq 0.9)$. In grey are the variables excluded from the PCA. In some pairs both variables are marked as excluded because of other high correlations they exhibited with different variables.

\begin{tabular}{ll}
\hline \multicolumn{2}{c}{ Variable pairs } \\
\hline INDith $|R| \geq 0.9$ \\
IND_DI & NORM_FCPMA65 \\
IND_DI & NORM_R20_65 \\
IND_DI & NORM_IR_PR \\
IND_DJ & NORM_R65 \\
IND_DT & NORM_R5_9 \\
IND_DT & NORM_R20_65 \\
IND_DT & NORM_IR_PR \\
IND_DT & NORM_R65 \\
NORM_FCPMA65 & IND_DI \\
NORM_IR_PR & NORM_R20_65 \\
NORM_NFF6 & NORM_FCPMA65 \\
NORM_R0_4 & NORM_FCPME15 \\
NORM_R0_4 & NORM_NFF6 \\
NORM_R20_65 & NORM_FCPMA65 \\
NORM_R5_9 & NORM_FCPME15 \\
NORM_R65 & NORM_FCPME15 \\
NORM_R65 & NORM_FCPMA65 \\
NORM_R65 & NORM_R20_65 \\
NORM_R65 & NORM_IR_PR \\
NORM_PR & NORM_ER \\
NORM_FCD_0 & NORM_FCD_1 \\
NORM_IR_SAC & NORM_IR_EP \\
\hline
\end{tabular}

the set of indicators and variables introduced in the final index. The second discusses the index's capability to characterize flood social susceptibility index across the Portuguese territory and the main reasons behind its spatial distribution.

As described in the Methods section, the first variable selection step was to compute a correlation matrix based on the normalized variable values to identify cases of extreme multicollinearity $(|R| \geq 0.9)$. As shown in Table 2, several age-related variable pairs exhibited high correlation values. This was expected for several reasons:

1. Some variables often refer to very similar age groups:

a. the aged dependency index (IND_DI), the retired persons and pensioners (NORM_IR_PR) and the traditional families with people 65 and older (NORM_FCPMA65);

2. One variable is included in a broader one and can be the main responsible factor for its variance:

a. the youth dependency index (IND_DJ) and the resident population between 5 and 9 years old (NORM_R5_9);

b. the traditional families with people with younger than 15 (NORM_FCPME15) and the resident pop- 
ulation between 0 and 4 years old (NORM_R0_4) and 5 and 9 years old (NORM_R5_9);

c. the total dependency ratio (IND_DT) and the resident population over 65 years old (NORM_R65)

3. The two variables are inversely correlated, as is the case of the following:

a. the resident population over 65 and residents between 20 and 65 years old, since areas with a higher percentage of active population, usually have a smaller percentage of residents in the older age groups (typically the parishes located around cities) and vice versa (like the rural areas)

Since for all these cases maintaining the two variables would not add any extra information to the final model, one of the variables was excluded (variables marked in grey in Table 2). Preference was given, on the one hand, to variables with a broader scope and, on the other hand, a focus on floodsusceptible age groups (such as children and the elderly). An example is the selection of the dependency ratios and the traditional families' indicators over the different age groups of the resident population. The only exception was the exclusion of the age dependency ratio (IND_DI), because it was already highly correlated with other broad variables such as the total dependency ratio (IND_DT) and the traditional families with people 65 and older (NORM_FCPMA65). By adopting this strategy it was possible to exclude a wider number of variables and maintain only the more transversal ones with useful information in flood social susceptibility. Nevertheless, it should be noted that this type of analysis is subjective and therefore open to different interpretations.

Apart from the age-related variables, only three other collinear pairs were found, all inversely correlated, meaning that they are complementary variables:

a. exclusively residential buildings (NORM_ER) and mainly residential buildings (NORM_PR);

b. traditional families without unemployed members (NORM_FCP0) and traditional families with one unemployed members (NORM_FCP1);

c. not economically active population (NORM_IR_SAC) and employed population (NORM_IR_EP).

For each of these pairs the maintained variable was either the one with a higher representativity in the Portuguese territory (a and c) or a higher information content regarding flood social susceptibility (b).

This step excluded 11 variables, which meant only 28 were introduced into the PCA.

The first full model approach PCA provided an overall KMO statistic of approximately 0.7 , well above the 0.5 minimum threshold referred to in the Methods section.
Table 3. Excluded variables due to low individual KMO values $(<0.5)$ taken from the diagonal of the anti-image correlation matrix.

\begin{tabular}{l}
\hline $\begin{array}{l}\text { Excluded variables } \\
\text { (individual KMO }<0.5)\end{array}$ \\
\hline NORM_EORE \\
NORM_EPAT \\
NORM_IRD1E \\
GMMTCO \\
NORM_IRDNE \\
NORM_IRQA_110 \\
NORM_EARG \\
NORM_ER \\
\hline
\end{tabular}

This means that the variables have some common variance, and therefore the data set can be reduced using a factor analysis method like the PCA. This value progressively increased to a final value of 0.86 as the variables with individual KMO statistics lower than 0.5 were removed in a recursive way, following the order given in Table 3. Three of removed variables refer to building typology (NORM_EORE, NORM_EPAT and NORM_EARG): this is not surprising since most of the variables in the data set refer to socioeconomic characteristics of either individuals or families which might not correlate well with building-related variables. The remaining variables refer to income/unemployment (NORM_IRD1E, GMMTCO and NORM_IRDNE), one to education (NORM_IRQA_110) and another to building function (NORM_IRQA_110). Although any of these variables could help characterize flood social susceptibility, the decision to remove them took into consideration that other variables could provide similar information, like, for instance, in the case of building typology, the "buildings with concrete structure" (NORM_EBAR) variable.

Finally, as shown in Table 3, the off-diagonal values exclusion criteria also reduced the number of variables included in the final model. As in previous steps, the selection of the excluded variables within each pair took in consideration their relative territorial representativeness and their importance to characterize flood social susceptibility. For instance, the decision to keep the variable "residents with secondary education" (NORM_IRQA_200) and exclude the variables "residents with third cycle of basic education" (NORM_IRQA_130) and "residents with higher education" (NORM_IRQA_400) was based on two reasons: (a) it is a broader variable than NORM_IRQA_130 since it represents all stages of secondary education, and (b) in the opinion of the authors it represents a more significant cut-off education group, regarding social susceptibility to floods than NORM_IRQA_400.

After arriving at a set of the most representative variables to include in the final model, the PCA was recalculated. From 
Table 4. Variable pairs with off-diagonal anti-image correlation matrix values $>0.6$. In grey are the excluded variables based on this criterion.

\begin{tabular}{ll}
\hline \multicolumn{2}{c}{ Variable pairs } \\
\hline IND_DJ & NORM_FCPME15 \\
IND_DT & NORM_FCPMA65 \\
PERC_AREAURB_FREG & DENS_POP \\
IND_DJ & NORM_R10_13 \\
NORM_IRQA_200 & NORM_IRQA_130 \\
NORM_IRQA_400 & NORM_IRQA_200 \\
\hline
\end{tabular}

all the calculated components, three were selected to define the main flood social susceptibility indicators that will compose the SSI (Table 5). These three components were the only ones with eigenvalues higher than 1, explaining approximately $63 \%$ of the total data set variability. Table 5 shows the correspondence between original variables and components based on their higher loadings. The definition of the three flood social susceptibility indicators represented by these components resulted from an interpretation of their main variables:

1. Regional conditions included most of the education variables (NORM_IRQA_001, NORM_IRQA_120, NORM_IRQA_200, NORM_IRQA_300) as well as an income variable related to average annual value of pensions (VMAP), a population density variable (DENS_POP) able to differentiate urban and rural areas and a building typology variable that identifies areas with higher or lower presence of concrete-based buildings. As referred to above in the description of the study area, all these variables can help characterize the significant regional inequalities between less susceptible coastal urban areas and the more vulnerable inland regions. Furthermore, those variables can also help distinguish, within the inland areas, some important urban areas from the remaining rural territory. The assumption of a higher vulnerability in inland regions is mainly associated with lower education and income levels and higher distance to institutions that provide assistance during and after flood events.

2. Age includes all variables related to more susceptible age groups (the children - NORM_FCPME15 - and the elderly - NORM_FCPMA65) as well as the more resilient (active population - NORM_IR_EP).

3. Social exclusion is defined by variables characterizing the lower income (NORM_RSI_Total, NORM_Edif_habit_Social) or possibly less integrated immigrant communities (NORM_Imigrantes_Varios).

Finally, for each indicator, up to two variables with a positive influence on flood social susceptibility and two with a
Table 5. Final components and their corresponding variable loadings. The name given to each component was based on the interpretation of the flood social susceptibility characterization given by the variable group that composes it.

\begin{tabular}{lrrr}
\hline & \multicolumn{3}{c}{ Component } \\
\cline { 2 - 4 } Variables & $\begin{array}{r}\text { Regional } \\
\text { conditions }\end{array}$ & Age & $\begin{array}{r}\text { Social } \\
\text { exclusion }\end{array}$ \\
\hline NORM_IRQA_001 & -0.647 & & \\
NORM_IRQA_120 & & 0.835 & \\
NORM_IRQA_200 & 0.882 & & \\
NORM_IRQA_300 & 0.753 & & \\
VMAP & 0.784 & & \\
DENS_POP & 0.715 & & \\
NORM_EBAR & 0.385 & & \\
NORM_R14_19 & & 0.747 & \\
NORM_FCPME15 & & 0.925 & \\
NORM_FCPMA65 & & -0.801 & \\
NORM_IR_EP & & 0.634 & 0.800 \\
NORM_Imigrantes_Varios & & & 0.432 \\
NORM_RSI_Total & & & 0.787 \\
NORM_Edif_habit_Social & & & \\
\hline
\end{tabular}

negative influence were selected to determine its final value. The selection was based on the highest loadings present in each indicator and in the interpretation of the role each variable played regarding flood social susceptibility (negative or positive influence). Table 6 shows the following: (a) the first indicator uses two different positive variables (higher value, lower susceptibility) to characterize education and income (residents with secondary education (NORM_IRQA_200) and average annual value of pensions (VMAP)) and only one negative variable (higher value, higher susceptibility) to characterize the presence of populations with lower education (residents with no qualification, NORM_IRQA_001); (b) in the age indicator the selected positive variable is related to the presence of people in active age, usually less susceptible to floods and the two negative variables are related to the existence of higher susceptible age groups (children under 15 and elderly over 65 years old); (c) the social exclusion indicator is composed of two negative indicators related to the presence of immigrant lower-income communities, which is understandable since it is an indicator aimed at characterizing highly vulnerable populations.

The maps with the results, per parish, of each indicator and the aggregated index are shown in Figs. 2 and 3. All indicator maps use a common scale of equal 0.1 intervals between -1 (higher susceptibility) and 1 (lower susceptibility). The SSI index final map also uses a 0.1 equal interval scale between -1.5 and 1.5. Although the indicators do not cover the full scale range, the definition of a common scale facilitates indicator interpretation, intercomparison and the characterization of their relative influence to the final index.

The regional conditions indicator, related to education and income variables, expresses the significant regional inequal- 

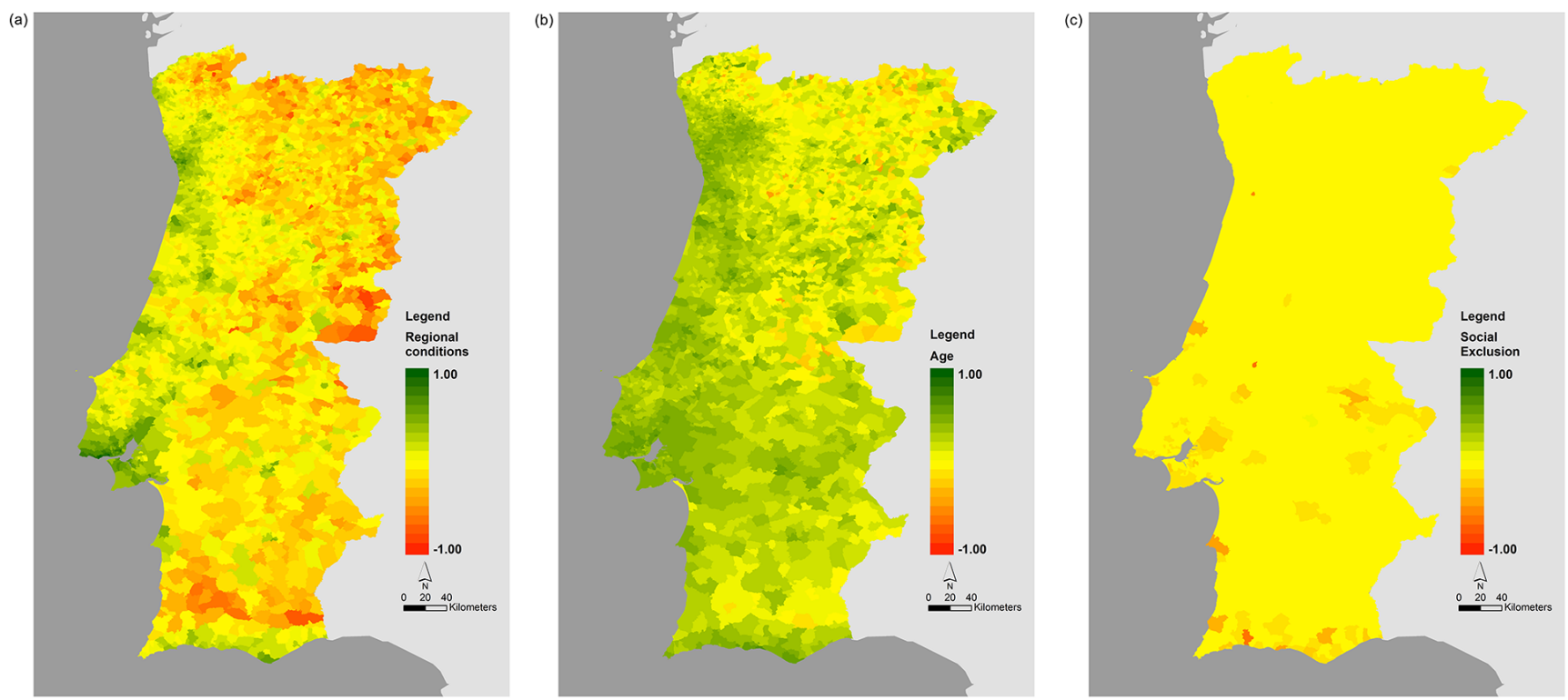

Figure 2. Maps of the three flood social susceptibility indicators for the continental Portuguese territory: (a) regional conditions, (b) age, and (c) social exclusion.

Table 6. Final set of variables included in each indicator that composed the final flood SSI.

\begin{tabular}{lll}
\hline Indicators & \multicolumn{2}{c}{ Final index variables } \\
\cline { 2 - 3 } & Positive influence on FSS & Negative influence on FSS \\
\hline $\begin{array}{l}\text { Regional } \\
\text { conditions }\end{array}$ & NORM_IRQA_200 & NORM_IRQA_001 \\
\hline Age & NORM_IR_EP & NORM_FCPME15 \\
& & NORM_FCPMA65 \\
\hline $\begin{array}{l}\text { Social } \\
\text { exclusion }\end{array}$ & & NORM_Imigrantes_Varios \\
\hline
\end{tabular}

ities described in the Study area section. The lower susceptibility values are concentrated in the Setúbal-Viana do Castelo coastal axis and along Algarve coastline (see Fig. 2). Those correspond to the more developed Portuguese regions, where the population has higher education and income levels. The major inland urban centres, where most of the youth population of the surrounding rural areas migrated to in search of better work conditions, also present low susceptibility values. The higher susceptibility values are associated with rural inland areas with a more fragile economy and an aging population.

This territorial dichotomy is also present in the age indicator, although the higher values are mostly focused in the centre and North inland regions, due to a lower presence of individuals in active age and a higher incidence of elderly rural populations. In the northern part of Alentejo the aging population factor is partially absorbed by the higher presence of people in active age.

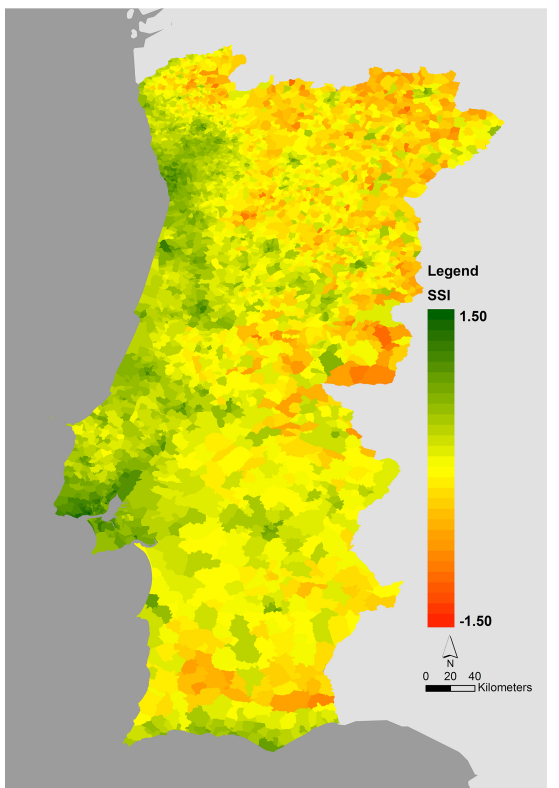

Figure 3. Flood social susceptibility index (SSI) for the continental Portuguese territory.

Finally the social exclusion indicator shows a more limited territorial influence, concentrated in the southern regions with a high incidence of low income and immigrant communities.

The SSI index compiles the partial information given by its indicators, highlighting, as expected, the coastal/inland differences and showing a higher ability to cope with floods in the more populated and developed coastal urban centres 
along the Atlantic coast. Within those areas, the metropolitan regions of Lisbon and Oporto have the lowest SSI values, mainly due to their higher per capita incomes and education and lower unemployment. Higher social susceptibility values are located in the poorer inland regions, with a focus on the north and centre eastern quadrant and the northern and southern part of Alentejo.

\section{Conclusions}

The main objective of this work was to develop a flood social susceptibility index for the continental Portuguese territory based on the most representative variables able to characterize different influencing factors such as age, income, education and building typology. This goal was achieved effectively using a PCA-based methodology to reduce the original set of 42 variables to eight, representing three indicators used in the final index: regional conditions, which aggregated income and education variables; age with parameters related to susceptible age groups; and social exclusion characterizing particularly susceptible very low-income and immigrant communities. The PCA-based technique avoided successfully most of the subjective selection processes based on expert analysis methodologies that can add bias to the final index, based on personal assumptions. Nevertheless some degree of subjectivity is unavoidable in different steps of this methodology, namely in the definition of the role given to each variable to characterize flood social susceptibility. An optimization of this process could only be achieved by the existence of flood effect validation data for the Portuguese territory, since it would corroborate the selection of the final set of variables included in the index and their respective role.

The use of a restrict set of variables contributed to index simplicity and consequently to its transparency, as shown in the straightforward interpretation of the results given in the previous section. In general, the index correctly identified populations more socially susceptible to floods, mostly concentrated in rural inland areas with lower income and education levels, when compared with the coastal region between Viana do Castelo and Setúbal.

Nevertheless, as referred to above, this index would benefit in the future from a validation procedure similar to the one developed by Feteke (2010). This study correlated questionnaire answers given by people affected by floods in Germany with the variables in the main PCA components to choose the variables to include in the index. The main reason not to pursue this methodology in the work presented here was the lack of systematized information on flood events in Portugal. Future integration with the results of projects like DISASTER (GIS database on hydro-geomorphologic disasters in Portugal: a tool for environmental management and emergency planning - http://riskam.ul.pt/disaster/) can improve this type of information and provide a good framework for an extensive nationwide validation of the current SSI.

Acknowledgements. We acknowledge (a) Ângela Antunes for her contribution and (b) APS - Portuguese Association of Insurers, who funded the project.

Edited by: V. Artale

Reviewed by: two anonymous referees

\section{References}

Armaş, I. and Gavriş, A.: Social vulnerability assessment using spatial multi-criteria analysis (SEVI model) and the Social Vulnerability Index (SoVI model) - a case study for Bucharest, Romania, Nat. Hazards Earth Syst. Sci., 13, 14811499, doi:10.5194/nhess-13-1481-2013, 2013.

Azar, D. and Rain, S.: Identifying population vulnerable to hydrological hazards in san juan, puerto rico, Geojournal, 69, 23-43, 2007.

Balica, S. F., Wright, N. G., and Meulen, F.: A flood vulnerability index for coastal cities and its use in assessing climate change impacts, Nat. Hazards, 64, 73-105, 2012.

Birkmann, J.: Measuring vulnerability to natural hazards - towards disaster resilient societies, United Nations University Press, Tokyo, Japan, 720 pp., 2006.

Cutter, S. L., Boruff, B. J., and Shirley, W. L.: Social vulnerability to environmental hazards, Social science quarterly, 84, 242-261, 2003.

Cutter, S. L., Mitchell, J. T., and Scott, M. S.: Revealing the vulnerability of people and places: a case study of georgetown county, south carolina, Annals of the association of american geographers, 90, 713-737, 2000.

EEA, WHO and JRC: Impacts of europe's changing climate - 2008 indicator-based assessment, Copenhagen, Denmark, European Environment Agency, 2008.

Fekete, A.: Assessment of social vulnerability to river floods in Germany, Bonn, university institute for environment and human security (unu-ehs), 2010.

Field, A.: Discovering statistics using spss, sage publications, 856 pp., 2007.

Ge, Y., Dou, W., Gu, Z., Qian, X., Wang, J., Xu, W., Shi, O., Ming, X., Zhou, X., and Chen, Y.: Assessment of social vulnerability to natural hazards in the yangtze river delta, china, Stoch. Env. Res. Risk A, 27, 1899-1908, 2013.

Hov, Ø., Cubasch, U., Fischer, E., Höppe, P., Iversen, T., Kvamstø, N. G., Kundzewicz, Z., Rezacova, D., Rios, D., Santos, F. D., Schädler, B., Veisz, O., Zerefos, C., Benestad, R., Murlis, J., Donat, M., Leckebusch, G., and Ulbrich, U.: Extreme weather events in europe: preparing for climate change adaptation. Banson production, cambridge, cb1 2bh, uk ed. Norway: the norwegian academy of science and letters, 136 pp., 2013.

Hutcheson, G. D. and Sofroniou, N.: The multivariate social scientist: introductory statistics using generalized linear models, sage publications, London, 276 pp., 1999.

IGP: Carta de uso e ocupação do solo de portugal para 2007 (cos 2007) - memória descritiva, Lisboa, 2010. 
INE: Statistical yearbook of alentejo region 2010, instituto nacional de estatística, i.p., 2010a.

INE: Statistical yearbook of algarve region 2010, instituto nacional de estatística, i.p., 2010b.

INE: Statistical yearbook of centro region 2010, instituto nacional de estatística, i.p., 2010c.

INE: Statistical yearbook of lisboa region 2010, instituto nacional de estatística, i.p., $2010 d$.

INE: Statistical yearbook of norte region 2010, instituto nacional de estatística, i.p., 2010e.

INE: Censos 2011 - resultados provisórios, instituto nacional de estatística, i.p., 2011.

Ionescu, C., Klein, R. T., Hinkel, J., Kavi Kumar, K. S., and Klein, R.: Towards a formal framework of vulnerability to climate change, Environ. Model. Assess., 14, 1-16, 2009.

IPCC: Managing the risks of extreme events and disasters to advance climate change adaptation, in: special report of the intergovernmental panel on climate change, edited by: Field, C. B., Barros, V., Stocker, T. F., Dahe, Q., Dokken, D. J., Ebi, K. L., Mastrandrea, M. D., Mach, K. J., Plattner, G.-K., Allen, S. K., Tignor, M., And Midgley, P. M., Cambridge univeristy press ed.: first joint session of working groups i and ii, 2012.

Jacinto, R., Grosso, N., Reis, E., Dias, L., Santos, F. D., and Garrett, P.: Continental Portuguese Territory Flood Susceptibility Index contribution to a vulnerability index, Nat. Hazards Earth Syst. Sci., 15, 1907-1919, doi:10.5194/nhess-15-1907-2015, 2015.
Kaiser, H.: An index of factorial simplicity, Psychometrika, 39, 3136, 1974.

Saaty, T. L.: Analytic hierarchy process: planning, priority setting, resource allocation, mcgraw hill higher education, 161-167, 1980.

Schanze, J., Zeman, E., and Marsalek, J.: Flood risk management: hazards, vulnerability and mitigation measures, Springer Netherlands, 67, 319 pp., 2006.

Sebald, C.: Towards an integrated flood vulnerability index - a flood vulnerability assessment, Msc, University of Twente, Enschede, the Netherlands, 82 pp., 2010.

Thywissen, K.: Core terminology of disaster reduction: a comparative glossary, edited by: Birkmann, J., in: Measuring vulnerability to natural hazards: towards disaster resilient societies, New york, Tokyo: United Nations University Press, 448-496, 2006.

Veen, A. V. D., Dopheide, E., Parker, D., Tapsell, S., Handmer, J., Gregg, C., Bonadonna, C., and Ferrara, F. F.: Del. 1.1.3 state-ofart on vulnerability of socio-economic systems (ensure project), Enhancing resilience of communities and territories facing natural and na-tech hazards, 100 pp., 2009.

Vörösmarty, C. J., Bravo de Guenni, L., Wollheim, W. M., Pellerin, B., Bjerklie, D., Cardoso, M., d'Almeida, C., Green, P., and Colon, L.: Extreme rainfall, vulnerability and risk: a continentalscale assessment for south america, Philosophical transactions of the royal society a: mathematical, physical and engineering sciences, 371, 2013. 